\title{
Delta neutrophil index and C-reactive protein: a potential diagnostic marker of multisystem inflammatory syndrome in children (MIS-C) with COVID-19
}

\author{
Cuneyt Karagol ${ }^{1}$ (1) - Ali Kansu Tehci ${ }^{2}$ - Ali Gungor ${ }^{2}$ - Zahide Ekici Tekin ${ }^{1}$ - Elif Çelikel ${ }^{1} \cdot$ Fatma Aydın $^{1}$. \\ Tuba Kurt $^{1}$ - Müge Sezer ${ }^{1}$ - Nilüfer Tekgöz ${ }^{1}$. Serkan Coşkun ${ }^{1}$ - Melike Mehveş Kaplan ${ }^{1}$. Gulsum Iclal Bayhan ${ }^{3}$. \\ Husniye Nese Yaralı ${ }^{4}$ Namuk Yasar Ozbek ${ }^{4}$ Banu Çelikel Acar ${ }^{1}$
}

Received: 11 May 2021 / Revised: 2 September 2021 / Accepted: 3 October 2021 / Published online: 14 October 2021

(c) The Author(s), under exclusive licence to Springer-Verlag GmbH Germany, part of Springer Nature 2021

\begin{abstract}
Multisystem inflammatory syndrome in children (MIS-C) is a life-threatening hyperinflammation syndrome emerging after COVID-19. The serum delta neutrophil index (DNI) reflects the fraction of circulating immature granulocytes and is evaluated in infection and inflammation. The aim of this study is to evaluate the usefulness of DNI as a diagnostic marker in patients with MIS-C and to assess its role in determining the severity of MIS-C. This retrospective, observational study included 83 patients with MIS-C and 113 patients with COVID-19, and 102 healthy controls. C-reactive protein (CRP), the absolute neutrophil count (ANC), absolute lymphocyte count (ALC), DNI, and the platelet count were recorded. The DNI levels were $4.60 \pm 5.70 \%$ in the MIS C group, $0.30 \pm 0.99 \%$ in the COVID group, and $0.20 \pm 0.56 \%$ in the control group $(p<0.001)$. According to the severity of MIS-C, the DNI level was found to be $1.22 \%$ in mild MIS-C, $4.3 \%$ in moderate MIS-C, and 5.7\% in severe MIS-C. There was a statistically significant correlation between DNI levels and the severity of MIS-C. The cutoff value of DNI for predicting MIS-C was $0.45 \%$. In the analysis of the diagnostic performance of DNI compared with CRP, ANC, ALC and platelet counts, sensitivity, specificity, positive predictive value, and negative predictive value were found to be $79.5 \%, 97.1 \%, 95.7 \%$, and $85.3 \%$, respectively.

Conclusions: The delta neutrophil index was identified as a diagnostic marker for MIS-C such as ANC, ALC, platelet count, and CRP. DNI levels in hemogram analysis may guide clinicians in determining the diagnosis and severity of MIS-C.

\section{What is Known:}

- Although CRP, sedimentation, ALC, ANC, platelet count, sodium, and albumin are used as first step tests, there is no specific laboratory marker used in the diagnosis of MIS C.

- The serum delta neutrophil index (DNI) reflects the fraction of circulating immature granulocytes and is elevated in infection and inflammation.

What is New:

- DNI is a promising and easily accessible marker that can be used with other markers in the diagnosis and determines the severity of MIS C.

- DNI is an easily accessible, inexpensive, and dynamic marker and its levels in simple hemogram analysis will guide pediatricians in determining the diagnosis and severity in MIS C.
\end{abstract}

Keywords Delta neutrophil index · Diagnostic marker · Hemogram · Multisystem inflammatory syndrome in children · Children · C-reactive protein

Communicated by Nicole Ritz

Cuneyt Karagol

1 Division of Pediatric Rheumatology, Department of Pediatrics, University of Health Sciences, Ankara City Hospital, 06800-Bilkent Ankara, Turkey

2 Department of Pediatric Emergency Medicine, Dr. Sami Ulus Maternity and Child Health and Diseases Training and Research Hospital, Ankara, Turkey
3 Division of Pediatric Infectious Disease, Department of Pediatrics, University of Health Sciences, Ankara City Hospital, 06800-Bilkent Ankara, Turkey

4 Division of Pediatric Hematology, Department of Pediatrics, University of Health Sciences, Ankara City Hospital, 06800-Bilkent Ankara, Turkey 


\section{Abbreviations}

$\begin{array}{ll}\text { ALC } & \text { Absolute lymphocyte count } \\ \text { ANC } & \text { Absolute neutrophil count } \\ \text { AUC } & \text { Area under the curve } \\ \text { CDC } & \text { The Centers for Disease Control and } \\ & \text { Prevention } \\ \text { COVID-19 } & \text { Coronavirus disease 2019 } \\ \text { CRP } & \text { C-reactive protein } \\ \text { DNI } & \text { Delta neutrophil index } \\ \text { ESR } & \text { Sedimentation rate } \\ \text { KD } & \text { Kawasaki disease } \\ \text { ROC } & \text { Receiver operating characteristic } \\ \text { RT-PCR } & \text { Reverse transcription polymerase chain } \\ & \text { reaction }\end{array}$

SARS-CoV-2 Severe acute respiratory syndrome coronavirus 2

$\begin{array}{ll}\text { SD } & \begin{array}{l}\text { Standard deviation } \\ \text { Multisystem inflammatory syndrome in } \\ \text { children }\end{array} \\ \text { MPO } & \begin{array}{l}\text { Myeloperoxidase } \\ \text { VIS }\end{array} \\ \text { Vasoactive-Inotropic Score }\end{array}$

\section{Introduction}

Coronavirus disease 2019 (COVID-19) spreads all over the world in a short time and became a global pandemic. In April 2020, there has been an apparent cluster of children presenting with similar symptoms like Kawasaki disease (KD), toxic shock syndrome, and secondary hemophagocytic lymphohistiocytosis associated with COVID-19 in Italy, the UK, and the USA [1-3]. This disease was later named multisystem inflammatory syndrome in children (MIS-C), and it is characterized by persistent fever, increased inflammatory laboratory tests, and multi-organ system involvement [4]. Researches are still ongoing to discover who will develop or progress to MIS-C after COVID-19.

Given the severity of MIS-C, its early diagnosis is essential. The use of indiscriminate over-testing should be avoided in evaluating patients with possible MIS-C, considering other possible causes of fever. A tiered diagnostic approach is recommended in MIS-C patients without life-threatening manifestations, this includes performing an initial screening evaluation (complete blood cell count with manual differential, erythrocyte sedimentation rate (ESR), C-reactive protein (CRP), testing for SARS-CoV-2 with reverse transcriptionpolymerase chain reaction (RT-PCR) or serology, and comprehensive metabolic panel), and proceeding to an advanced diagnostic work-up only in children whose cause of fever cannot be determined with initial laboratory tests [4-6].

Recently, immature granulocytes in peripheral blood have started to be counted automatically by cytochemical myeloperoxidase reaction and light beam reflection methods during the routine complete blood count. This parameter, called delta neutrophil index (DNI), shows the ratio of immature granulocytes in peripheral blood. This rate has been studied in various diseases such as sepsis, disseminated intravascular coagulation, urinary tract infection, and $\mathrm{KD}$ in the literature, and its use is recommended as a parameter that provides information about the clinical course, prognosis, evaluation of treatment success and mortality of these diseases [7, 8].

The aim of this study was to determine the value of DNI, which is an easily accessible and inexpensive marker in the diagnosis of MIS-C, and that is useful in determining the severity of MISC.

\section{Methods}

\section{Study design and participants}

We conducted this retrospective cross-sectional study in patients diagnosed with COVID-19 and MIS-C in Ankara City Hospital, Turkey, between March 2020 and January 2021. Local ethics committee approval was obtained prior to the study.

The study group consisted of 113 patients with COVID19 and 83 patients with MIS-C. During the study period, 113 patients aged $0-18$ years who presented with symptoms such as fever, cough, respiratory distress, and weakness and were diagnosed with COVID-19 were randomly selected to be included in this study. The COVID-19 diagnosis was confirmed by RTPCR detection of severe acute respiratory syndrome coronavirus 2 (SARS-CoV-2) in oro-nasopharyngeal swab samples.

Eighty-three patients between the ages of 0-18 diagnosed with MIS-C according to the diagnostic criteria of the Centers for Disease Control and Prevention (CDC) were included in the study. The CDC case definition for MIS-C was used to define a confirmed case of MIS-C, which is as follows: (1) an individual aged $<21$ years (2) presenting with fever ( $\geq 24 \mathrm{~h}$ ), at least examples of 2 laboratory evidence of inflammation (elevated CRP, ESR, fibrinogen, procalcitonin, D-dimer, ferritin, lactate dehydrogenase, interleukin 6, neutrophilia, lymphocytopenia, hypoalbuminemia), and evidence of clinically severe illness requiring hospitalization, with multisystem $(\geq 2)$ organ involvement (cardiovascular (e.g., shock, elevated cardiac enzymes), respiratory (e.g., pneumonia), renal (e.g., renal failure), neurological (e.g., seizure, stroke), gastrointestinal (e.g., abdominal pain, diarrhea, vomiting), dermatological (e.g., mucositis, rash)); (3) evidence of SARS-CoV-2 infection or exposure (positive SARS-CoV-2 RT-PCR or positive serology or positive antigen test or COVID-19 exposure within the 4 weeks prior to the onset of symptoms); and (4) exclusion of other potential causes including bacterial sepsis and staphylococcal/streptococcal toxic shock syndromes. All 83 patients in the MIS-C 
group were positive for serological testing for COVID-19 and met all 4 criteria and were thus diagnosed MIS-C.

The MIS-C patients were divided into three groups as mild, moderate, and severe according to the VasoactiveInotropic Score (VIS), degree of respiratory support, and evidence of organ damage. The vasoactive-Inotropic Score was manually calculated by evaluating the patient inotropic and vasopressor supports. (VIS $=$ dopamine dose $(\mu \mathrm{g} /$ $\mathrm{kg} / \mathrm{min})+$ dobutamine dose $(\mu \mathrm{g} / \mathrm{kg} / \mathrm{min})+100 \times$ adrenaline dose $(\mu \mathrm{g} / \mathrm{kg} / \mathrm{min})+100 \times$ noradrenaline dose $(\mu \mathrm{g} / \mathrm{kg} /$ $\mathrm{min})+10 \times$ milrinone dose $(\mu \mathrm{g} / \mathrm{kg} / \mathrm{min})+10.000 \times$ vasopressin dose $(\mathrm{U} / \mathrm{kg} / \mathrm{min}))$ [9].

The healthy controls consisted of 102 healthy children and were determined at least 1:1 ratio with the study group. The control group was selected from age- and sex-matched healthy children who had no acute or chronic disease that could cause inflammation and who had presented at the pediatric clinics of our hospital for other reasons. Patients with clinically important additional diseases (chronic lung disease, congenital heart failure, malignancy, etc.) and those whose medical records could not be obtained were excluded from the study.

\section{Data collection}

Clinical and laboratory data were retrieved from electronic records. Clinical data included demographics, the family history for SARS-CoV-2, presence of comorbidities, symptoms at presentation, and follow-up. The CRP, absolute neutrophil count (ANC), absolute lymphocyte count (ALC), DNI, and platelet count were recorded from the laboratory data. If a case had more than one hemogram, only the first, taken at hospital admission, was included in the study.

\section{Delta-Neutrophil Index}

Delta-Neutrophil Index levels were routinely studied in the complete blood count with the Siemens-ADVIA 2120 model automatic testing device. This hematological analyzer uses two independent leukocyte count methods: myeloperoxidase channel (MPO) and the lobularity/nuclear density channel. For DNI, the value obtained by the formula (leukocyte subfraction assayed using the MPO channel by cytochemical reaction)-(leukocyte subfraction assayed using the nuclear lobularity channel based on reflected light beam measurements) was determined as the ratio of immature granulocytes (myelocytes, metamyelocytes, and promyelocytes) in peripheral blood.

\section{Statistical analysis}

All the data were analyzed using the SPSS-2020 statistical package; categorical variables between groups were analyzed using the $\chi^{2}$ test. The comparison of means between two groups was examined by using a $t$-test and, Mann-Whitney $U$ test. Categorical variables are shown as number $(n)$ and percentage (\%), while continuous variables are shown as mean $( \pm)$ standard deviation (SD). ANOVA was used in the comparison of more than two groups, in normal distributions and the Kruskal-Wallis test for nonnormal distributions. Receiver operating characteristic (ROC) curve analysis was used to determine the power of variables in differentiating groups. The area under the curve (AUC) was calculated; significant cutoff levels and sensitivity, specificity, positive predictive, and negative predictive values were calculated using the Youden index. Since ALC and platelets decreased in MIS-C, "smaller test result indicates more positive test" was selected in the ROC analysis of these variables. In addition, logistic regression analysis was performed to assess the values of the variables in the diagnosis of MIS-C. We performed multivariate logistic regression analysis for those with $p<0.25$ in the univariate logistic regression analysis for each variable. Statistical significance was accepted as $p<0.05$ was deemed to indicate.

\section{Results}

Eighty-three patients with MIS-C and 113 patients with COVID-19, as well as 102 healthy controls, were included in the study. While there was male dominance in both groups, there was no significant difference between the groups in terms of gender. The mean age was $9.40 \pm 4.52$ in the MIS-C group, $10.35 \pm 5.64$ in the COVID-19 group, and $9.65 \pm 4.12$ in control group. The COVID-19 group had a significantly shorter length of hospital stay compared with the MIS-C group $(8.81 \pm 3.88$ days versus $16.58 \pm 8.34$ days, respectively; $p<0.001)$. In the MIS-C group $22(26.5 \%)$ patients, in the COVID-19 group, only $1(0.88 \%)$ patient was admitted into the intensive care unit (Table 1).

DNI levels at the time of diagnosis were $4.60 \pm 5.70 \%$ in the MIS-C group, $0.30 \pm 0.99 \%$ in the COVID- 19 group, and $0.20 \pm 0.56 \%$ in the control group $(p<0.001)$. According to the severity of MIS-C, DNI levels were found to be $1.22 \%$ $(0.1 \pm 2.6)$ in mild MIS-C, $4.3 \%(2.4 \pm 10.7)$ in moderate MIS$\mathrm{C}$, and $5.7 \%(2.8 \pm 12.2)$ in severe MIS-C. The highest DNI levels were found in severe MIS-C, followed by moderate and mild MIS-C, and the difference between groups was found to be significant $(p<0.001)$. Similarly, CRP, ANC, ALC, and platelet levels were higher in the MIS-C group, and this difference was found to be significant between the groups (Tables 2 and 3 ).

The diagnostic performance of DNI in patients with MIS-C was evaluated and the cutoff value of DNI was found to be $0.45 \%$ (AUC 0.893) (Fig. 1); sensitivity, specificity, the positive predictive value, and negative predictive value of DNI 
Table 1 Demographic features of the patients

\begin{tabular}{lllll}
\hline & $\begin{array}{l}\text { Patients with } \\
\text { MIS-C }(n=83)\end{array}$ & $\begin{array}{l}\text { Patients with } \\
\text { COVID-19 }(n=113)\end{array}$ & $\begin{array}{l}\text { Control } \\
(n=102)\end{array}$ & $P$ value \\
\hline DNI (mean+/-SD, \%) & $4.60 \pm 5.70$ & $0.30 \pm 0.99$ & $0.20 \pm 0.56$ & $P<0.001$ \\
DNI (min.-max, \%) & $0.1-32.6$ & $0.1-9.4$ & $0.1-1.9$ & \\
CRP $(\mathrm{mg} / \mathrm{dL})$ & $158.02 \pm 79.9$ & $8.10 \pm 17.07$ & $1.14 \pm 1.07$ & $P<0.001$ \\
ANC $\left(\times 1000 / \mathrm{mm}^{3}\right)$ & $9.19 \pm 5.85$ & $3.48 \pm 2.17$ & $3.57 \pm 1.80$ & $P<0.001$ \\
ALC $\left(\times 1000 / \mathrm{mm}^{3}\right)$ & $1.21 \pm 0.89$ & $2.41 \pm 1.81$ & $3.15 \pm 1.33$ & $P<0.001$ \\
Platelet $\operatorname{count}\left(\times 1000 / \mathrm{mm}^{3}\right)$ & $215.3 \pm 105.0$ & $262.8 \pm 81.9$ & $307.3 \pm 82.8$ & $P<0.001$ \\
\hline
\end{tabular}

\begin{tabular}{lllll}
\hline & $\begin{array}{l}\text { Patients with MIS-C } \\
(n=83)\end{array}$ & $\begin{array}{l}\text { Patients with COVID- } \\
19(n=113)\end{array}$ & $\begin{array}{l}\text { Control } \\
(n=102)\end{array}$ & $P$ value \\
\hline $\begin{array}{l}\text { Age (years), mean } \pm \text { SD } \\
\text { Gender, } n(\%)\end{array}$ & $9.40 \pm 4.52$ & $10.35 \pm 5.64$ & $9.86 \pm 6.58$ & $P>0.005$ \\
Male & $47(56.6)$ & $60(53.1)$ & $56(54.9)$ & $P>0.005$ \\
Female & $36(43.3)$ & $52(46.9)$ & $46(45.1)$ & \\
Length of hospital stay & $16.58 \pm 8.34$ & $8.81 \pm 3.88$ & - & \\
$\quad$ (days), mean \pm SD & & & - & \\
$\begin{array}{l}I C U \text { admission }(n, \%) \\
\text { Severity of MIS-C, } n(\%)\end{array}$ & $22,26.5$ & $1,0.88$ & - \\
Mild & $41(49.3)$ & - & - & \\
Moderate & $23(27.7)$ & - & - & \\
Severe & $19(22.8)$ & - & & \\
\hline
\end{tabular}

$M I S-C$ multisystem inflammatory syndrome in children, $I C U$ intensive care unit
Table 2 Laboratory data of the patients. MIS-C multisystem inflammatory syndrome in children, $D N I$ delta neutrophil index, $C R P$ C-reactive protein, $A N C$ absolute neutrophil count, $A L C$ absolute lymphocyte count were found to be $79.5 \%, 97.1 \%, 95.7 \%$, and $85.3 \%$, respectively (Table 4). Additionally, logistic regression analysis showed that the use of DNI (odds ratio (OR) 29.9\% confidence interval (CI) 10.2-84.1) was associated with a diagnosis of MIS-C (Table 5).

\section{Discussion}

To the best of our knowledge, this is the first study in the literature on the diagnostic value of DNI in MIS-C. Early diagnosis and treatment of MIS-C are very important in reducing mortality and morbidity. A specific inflammatory marker that can be used in the diagnosis of MIS-C has not been reported yet. In this current study, the importance of DNI in the early diagnosis of MIS-C was evaluated, and it was shown that DNI is an effective marker in the diagnosis and determination of the severity of MIS-C.

The diagnostic value of inflammatory markers that can be used in the diagnosis of MIS-C has been previously evaluated in many studies. The American College of Rheumatology used increased ANC, decreased ALC, decreased platelet count, hyponatremia, and hypoalbuminemia that may accompany increased CRP and the ESR rate as the first step tests in the diagnosis of MIS-C [10].
These tests are easily accessible and affordable tests that pediatricians often prefer in their daily practice. In a metaanalysis, Zhao et al. showed that, when compared with active COVID-19 patients, there were changes in inflammatory markers, including ALC, ANC, platelet count,

Table 3 Inflammatory markers in the MIS-C group

\begin{tabular}{ll}
\hline & $\begin{array}{l}\text { Patients with MIS-C } \\
(n=83)\end{array}$ \\
\hline$C R P(\mathrm{mg} / \mathrm{dL})$ & $158.02 \pm 79.9$ \\
ANC $\left(\times 1000 / \mathrm{mm}^{3}\right)$ & $9.19 \pm 5.85$ \\
ALC $\left(\times 1000 / \mathrm{mm}^{3}\right)$ & $1.21 \pm 0.89$ \\
Platelet count $\left(\times 1000 / \mathrm{mm}^{3}\right)$ & $215.3 \pm 105.0$ \\
ESR $(\mathrm{mm} / \mathrm{h})$ & $43.7 \pm 27.2$ \\
PCT $(\mathrm{micg} / \mathrm{L})$ & $11.4 \pm 26.9$ \\
D Dimer $(\mathrm{mg} / \mathrm{L})$ & $5.31 \pm 9.08$ \\
Ferritin $(\mathrm{micg} / \mathrm{L})$ & $545.21 \pm 760.01$ \\
Fibrinogen $(\mathrm{g} / \mathrm{L})$ & $5.20 \pm 1.49$ \\
IL-6 $(\mathrm{pg} / \mathrm{ml})$ & $194.34 \pm 272.72$ \\
Lactate $(\mathrm{mmol} / \mathrm{L})$ & $2.60 \pm 1.62$ \\
Albumin $(\mathrm{g} / \mathrm{L})$ & $37.96 \pm 7.32$ \\
LDH $($ U/L $)$ & $307.06 \pm 93.60$ \\
Positive serology $(\mathrm{n}, \%)$ & 83,100 \\
\hline
\end{tabular}


Fig. 1 A ROC curves for DNI, CRP, and neutrophil. B ROC curves for platelet and lymphocytes. A, B Receiver operating characteristic curves for inflammatory markers in diagnosis of MIS-C. DNI, delta neutrophil index; CRP, C-reactive protein
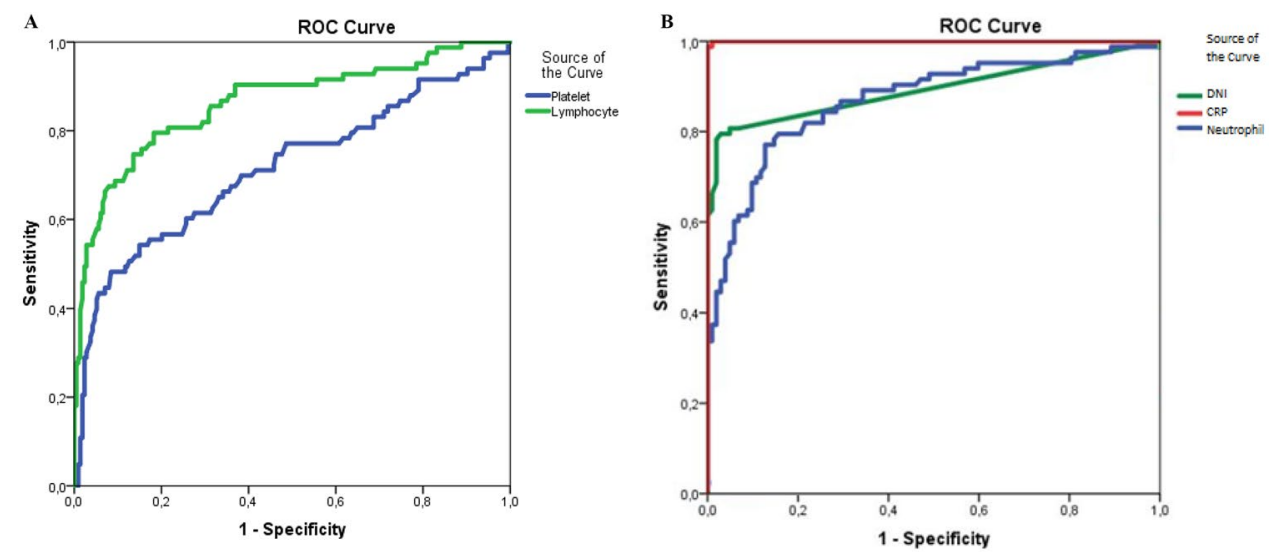

and CRP in 787 MIS-C patients, as a result of increased inflammatory response, excessive release of inflammatory mediators, and cytokine storm [11]. Similarly, in our study, increased CRP, decreased ALC, increased ANC, and decreased platelet count were found to be significant in the MIS-C group compared to the COVID-19 and control groups. Early release of immature neutrophils from the bone marrow into peripheral blood in correlation with inflammation has been reported, especially in many infectious diseases. Similarly, in COVID-19 patients, it has been reported that immature neutrophils increase in the circulation and are associated with increased inflammation and disease severity [12].
DNI is a simple test that can be quantitatively measured in routine complete blood counts. It has a diagnostic value in diseases such as pediatric sepsis, meningitis, appendicitis, urinary tract infection, and $\mathrm{KD}$; it has even been also reported to be an important marker in determining morbidity and mortality in these diseases [13-16]. Park et al. emphasized that DNI is a potentially useful diagnostic tool in infected patients and should be used more widely in clinical practice to predict mortality [7]. However, studies of DNI in COVID-19 patients are limited in the literature. Birben et al. showed that DNI is an effective predictor of the intensive care unit mortality in 388 COVID-19 adult patients [17]. In our study, the prognosis of MIS-C was not evaluated, but
Table 4 Diagnostic performance of laboratory markers in the diagnosis of MIS-C. DNI, delta neutrophil index; CRP, C-reactive protein; ANC, absolute neutrophil count; ALC, absolute lymphocyte count

Table 5 Logistic regression analysis for diagnosis of MIS-C

\begin{tabular}{lrlllll}
\hline & Cutoff & AUC & $\begin{array}{l}\text { Sensitivity } \\
(\%)\end{array}$ & $\begin{array}{l}\text { Specificity } \\
(\%)\end{array}$ & $\begin{array}{l}\text { Positive } \\
\text { predictive } \\
\text { value }(\%)\end{array}$ & $\begin{array}{l}\text { Negative } \\
\text { predictive value } \\
(\%)\end{array}$ \\
\hline DNI $(\%)$ & 0.45 & 0.893 & 79.5 & 97.1 & 95.7 & 85.3 \\
CRP $(\mathrm{mg} / \mathrm{dL})$ & 5.00 & 1.00 & 99.9 & 99.9 & 98.8 & 99.9 \\
ANC $\left(\times 1000 / \mathrm{mm}^{3}\right)$ & 4.35 & 0.870 & 84.3 & 74.5 & 72.9 & 85.4 \\
ALC $\left(\times 1000 / \mathrm{mm}^{3}\right)$ & 1.00 & 0.863 & 54.2 & 97.2 & 99.8 & 72.9 \\
Platelet count $\left(\times 1000 / \mathrm{mm}^{3}\right)$ & 150.00 & 0.715 & 30.1 & 97.2 & 96.2 & 63.5 \\
\hline
\end{tabular}

$D N I$ delta neutrophil index, $C R P$ C-reactive protein, $A N C$ absolute neutrophil count, $A L C$ absolute lymphocyte count

\begin{tabular}{|c|c|c|c|c|c|c|}
\hline \multirow[b]{2}{*}{ Variables } & \multicolumn{3}{|c|}{$\begin{array}{l}\text { Univariate regression } \\
\text { analysis }\end{array}$} & \multicolumn{3}{|c|}{ Multivariate regression analysis } \\
\hline & OR & $95 \% \mathrm{CI}$ & $p$ value & OR & $95 \%$ CI & $p$ value \\
\hline$C R P>5 \mathrm{mg} / \mathrm{dL}$ & 372 & 0 & 0,994 & - & - & - \\
\hline$D N I>0.45 \%$ & 79.2 & $34.5-181.4$ & $<0.01$ & 29.29 & $10.2-84,1$ & $<0.01$ \\
\hline$A N C>4,35 \times 1000 / \mathrm{mm}^{3}$ & 14.83 & $7.6-28,8$ & $<0.01$ & 16.84 & $5.1-55,0$ & $<0.01$ \\
\hline$A L S<1 \times 1000 / \mathrm{mm}^{3}$ & 41.05 & $16.3-102.9$ & $<0.01$ & 27.89 & $5.7-134,7$ & $<0.01$ \\
\hline Platelet $<150 \times 1000 / \mathrm{mm}^{3}$ & 14.94 & $5.8-38.1$ & $<0.01$ & 7.55 & $1.5-38.0$ & 0.014 \\
\hline
\end{tabular}

$O R$ odds ratio, $C I$ confidence interval, $D N I$ delta neutrophil index, $C R P$ C-reactive protein, $A N C$ absolute neutrophil count, $A L C$ absolute lymphocyte count 


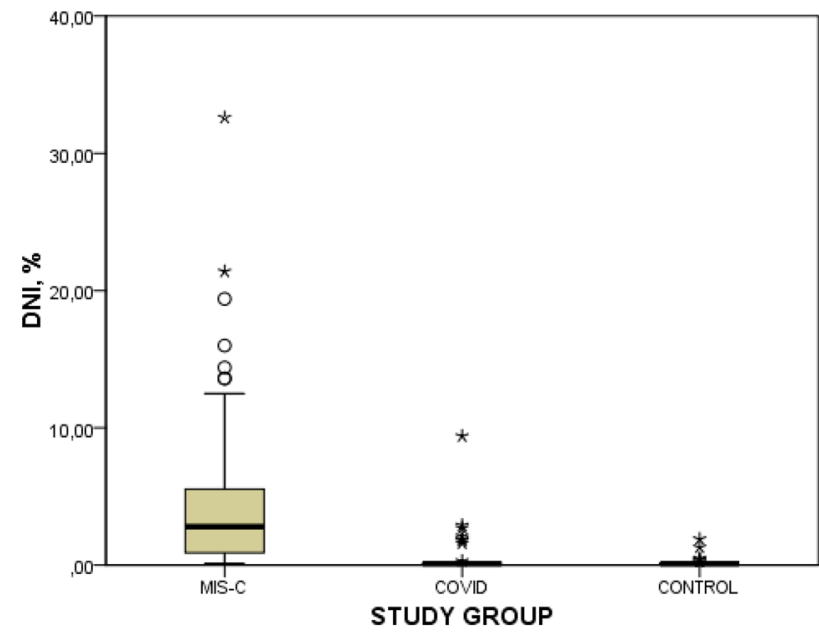

Fig. 2 DNI levels of patients. MIS-C, multisystem inflammatory syndrome in children; DNI, delta neutrophil index

DNI levels were found to be correlated with disease severity (Fig. 2). Delta neutrophil index cutoff levels were $0.45 \%$ for MIS-C. It is important to pay attention to both this cutoff value and to be aware that the increase in the DNI level is related to the severity of MIS-C. Prediction of the MIS-C severity based on the DNI level at the time of diagnosis may affect the management of the patient and the choice of treatment.

MIS-C is a new phenomenon that causes multiorgan involvement together with cardiac involvement and hemodynamic instability. Monitoring of inflammatory markers in patients diagnosed with MIS-C is important in determining early diagnosis and treatment of patients who may require critical care [18]. The majority of children affected are RT-PCR negative for SARS-CoV-2 virus but are antibody positive, indicating a post-infectious inflammatory response following SARS-CoV-2 infection. However, in some of the patients, both RT-PCR and serology tests are positive. Although it is known that there are clinical and laboratory findings specific to MIS-C, if RT-PCR is found positive for SARS-CoV-2 in MIS-C patients, differentiating COVID-19 from MIS-C may be challenging for the clinician. The optimal inflammatory markers to demonstrate the difference in these diseases are still unclear. Some laboratory findings of active COVID-19 and MIS-C are similar (e.g., lymphopenia, increased CRP). In our study, it was shown that the DNI at the time of diagnosis was significantly higher in MIS-C compared to COVID-19. Moreover, the simple scoring system we created in our study, which can only be calculated with basal laboratory tests and DNI, may contribute to the diagnosis of MIS-C.

Our study has several limitations, first of all, it was designed as a retrospective study. In addition, a limited number of inflammatory markers such as ANC, ALC,
CRP, and platelet count were evaluated in our study. Finally, the high DNI levels in the study group patients and controls were not confirmed by flow cytometry or peripheral smear. However, our study is the first study in the literature evaluating DNI in MIS-C patients and contributes to the literature with its significant results.

In conclusion, early diagnosis and management are important for optimal outcomes in children affected with MIS-C. To predict MIS-C, the best AUC values were associated with CRP, DNI, ANC, and ALC. Because it does not require taking extra blood, easy-to-measure DNI may be used in the diagnosis of patients with MIS-C. Diagnostic tests have not been clearly established in MIS-C, DNI levels in simple hemogram analysis will guide pediatricians in determining the diagnosis and severity. On the other hand, randomized, long-term follow-up studies with larger patient groups are required to demonstrate the role of DNI.

Authors' contributions CK: conceptualization, study design, writingoriginal draft, writing-review and editing, read and approved the final manuscript, drafted the initial manuscript. AKT, AG: conceptualization, data analysis, read and approved the final manuscript. ZET, EC, FA, TA, MS, NT, SC, MMK: acquisition of data, writing-original draft, read and approved the final manuscript. GIBB, HNY, NYO: writingreview and editing, read and approved the final manuscript. BCA: conceptualization, writing-original draft, writing-review and editing, read and approved the final manuscript.

Availability of data and material The data sets analyzed during the current study are available from the corresponding author on reasonable request. Data can be provided after the article is published.

Code availability N/A.

\section{Declarations}

Ethics approval Approval was obtained from the ethical review committee of the Ankara City Hospital. (Registration number: E1-20-576).

\section{Consent to participate N/A}

Consent for publication This manuscript is not under simultaneous consideration by any other publication. All authors have approved the final manuscript and take full responsibility for the manuscript.

Conflict of interest The authors declare no competing interests.

\section{References}

1. Riphagen S, Gomez X, Gonzalez-Martinez C, Wilkinson N, Theocharis P (2020) Hyperinflammatory shock in children during COVID-19 pandemic. Lancet (London, England) 395(10237):1607-1608. https://doi.org/10.1016/S0140-6736(20) 31094-1

2. Viner RM, Whittaker E (2020) Kawasaki-like disease: emerging complication during the COVID-19 pandemic. Lancet (London, 
England) 395(10239):1741-1743. https://doi.org/10.1016/S01406736(20)31129-6

3. Verdoni L, Mazza A, Gervasoni A, Martelli L, Ruggeri M, Ciuffreda $M$ et al (2020) An outbreak of severe Kawasaki-like disease at the Italian epicentre of the SARS-CoV-2 epidemic: an observational cohort study. Lancet (London, England) 395(10239):1771-1778. https://doi.org/10.1016/S0140-6736(20)31103-X

4. Feldstein LR, Rose EB, Horwitz SM, Collins JP, Newhams MM, Son $M$ et al (2020) CDC COVID-19 Response Team (2020). Multisystem inflammatory syndrome in U.S. children and adolescents. N Engl J Med 383(4):334-346. https://doi.org/10.1056/ NEJMoa2021680

5. Aydın F, Çelikel E, Ekici Tekin Z, Coşkun S, Sezer M, Karagöl $C$ et al (2021) Comparison of baseline laboratory findings of macrophage activation syndrome complicating systemic juvenile idiopathic arthritis and multisystem inflammatory syndrome in children. Int J Rheum Dis 24(4):542-547. https://doi.org/10.1111/ 1756-185X.14078

6. Tang Y, Li W, Baskota M, Zhou Q, Fu Z, Luo Z et al (2021) Multisystem inflammatory syndrome in children during the coronavirus disease 2019 (COVID-19) pandemic: a systematic review of published case studies. Transl Pediatr 10(1):121-135. https:// doi.org/10.21037/tp-20-188

7. Park JH, Byeon HJ, Lee KH, Lee JW, Kronbichler A, Eisenhut M et al (2017) Delta neutrophil index (DNI) as a novel diagnostic and prognostic marker of infection: a systematic review and metaanalysis. Inflamm Res 66(10):863-870. https://doi.org/10.1007/ s00011-017-1066-y

8. Park BH, Kang YA, Park MS, Jung WJ, Lee SH, Lee SK et al (2011) Delta neutrophil index as an early marker of disease severity in critically ill patients with sepsis. BMC Infect Dis 11:299. https://doi.org/10.1186/1471-2334-11-299

9. Girona-Alarcon M, Bobillo-Perez S, Sole-Ribalta A, Hernandez L, Guitart C, Suarez R, Balaguer M, Cambra FJ, Jordan I (2021) KIDS-Corona study group; Kids corona platform. The different manifestations of COVID-19 in adults and children: a cohort study in an intensive care unit. BMC Infect Dis 21(1):87. https://doi.org/ 10.1186/s12879-021-05786-5

10. Centers for Disease Control and Prevention (2019) Novel coronavirus, Wuhan, China. Information for Healthcare Professionals. https://www.cdc.gov/coronavirus/2019-nCoV/hcp/index.html. Accessed 14 February 2020
11. Zhao Y, Yin L, Patel J, Tang L, Huang Y (2021) The inflammatory markers of multisystem inflammatory syndrome in children (MIS-C) and adolescents associated with COVID-19: a meta-analysis. J Med Virol. https://doi.org/10.1002/jmv.26951

12. Carissimo G, Xu W, Kwok I, Abdad MY, Chan YH, Fong SW et al (2020) Whole blood immunophenotyping uncovers immature neutrophil-to-VD2 T-cell ratio as an early marker for severe COVID-19. Nat Commun 11(1):5243. https://doi.org/10.1038/ s41467-020-19080-6

13. Seok Y, Choi JR, Kim J, Kim YK, Lee J, Song J et al (2012) Delta neutrophil index: a promising diagnostic and prognostic marker for sepsis. Shock (Augusta, Ga.) 37(3):242-246. https://doi.org/ 10.1097/SHK.0b013e3182454acf

14. Kim OH, Cha YS, Hwang SO, Jang JY, Choi EH, Kim HI et al (2016) The use of Delta Neutrophil Index and Myeloperoxidase Index for predicting acute complicated appendicitis in children. PLoS ONE 11(2):e0148799. https://doi.org/10.1371/journal.pone.0148799

15. Nam M, Son BH, Seo JE, Kim IR, Park CK, Kim HK (2018) Improved diagnostic and prognostic power of combined Delta Neutrophil Index and mean platelet volume in pediatric sepsis. Ann Clin Lab Sci 48(2):223-230

16. Lee SH, Ko KO, Lim JW, Yoon JM, Song YH, Lee JW et al (2019) Delta-neutrophil index: a potential predictor of coronary artery involvement in Kawasaki disease by retrospective analysis. Rheumatol Int 39(11):1955-1960. https://doi.org/10.1007/ s00296-019-04448-9

17. Birben B, Birben OD, Akın T, Akkurt G, Surel AA, Yakısık E et al (2021) Efficacy of the delta neutrophil index in predicting 30-day mortality in COVID-19 patients requiring intensive care. Int J Clin Pract 75(5):e13970. https://doi.org/10.1111/ijcp.13970

18. Whittaker E, Bamford A, Kenny J, Kaforou M, Jones CE, Shah P et al (2020) PIMS-TS Study Group and EUCLIDS and PERFORM Consortia. Clinical characteristics of 58 children with a pediatric inflammatory multisystem syndrome temporally associated with SARS-CoV-2. JAMA 324(3):259-269. https://doi.org/10.1001/ jama.2020.10369

Publisher's Note Springer Nature remains neutral with regard to jurisdictional claims in published maps and institutional affiliations. 